\title{
COLLABORATIVE INNOVATION
}

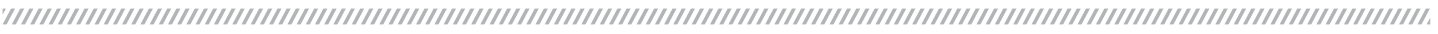

\section{Dear Readers,}

More and more organisations are coming to realise that innovation is key for them and their businesses to remain competitive and relevant in the foreseeable future. And they realise that the onus on making that happen lies not just with their own employees, but by harnessing innovation from the external environment. The answer, suggests experts, lies in collaborations.

A World Economic Forum (WEF) study on "Collaborative Innovation - Transforming Business, Driving Growth”, published in 2015 quoted Ellen Kullman, Chair of the Board and CEO, DuPont as saying that a single company cannot solve the world's most difficult challenges alone. Another report by Oliver Wyman recommends that the management create an open environment that strengthens the collaborative innovation culture in organisations, increase the competence level of its employees and supports entrepreneurial action in the R\&D department.

There is a lot of talk around the subject of collaborative innovation. But how is it approached in the Indian context - by the corporates, academia and policy makers? At a recent industry-academia forum, this was a subject of intense discussion. What impedes collaborative innovation in the country? Barring a few sectors, there seems to be a lack of initiative in the country from various stakeholders. Trust, especially over issues of intellectual property, has always been a grey area. In many cases, there seems to be a lack of clarity in what is expected or desired of the partners.

A recent India Innovation Study conducted by Bertelsmann Stiftung on India's emerging innovation landscape and prospects for collaboration with Germany, points out that despite India housing nearly 1,000 R\&D centres for leading multinationals, the country's spend on R\&D as a percentage of GDP at $0.9 \%$ is significantly lower compared to China's $1.95 \%$ and South Korea's $3.6 \%$. It further notes that India ranks relatively low on a variety of innovation and related indicators.

There is a definite focus on the part of the government to improve the country's innovation ecosystem. However, to foster an environment for long-term strategic partnerships, it is desirable to have a sustained policy framework. To address specific concerns or challenges of national interest and importance, the government should take a collaborative approach by involving all stakeholders. That, hopefully, will be the approach India takes in the immediate future.

P.S.: We are extremely pleased and honoured to announce the formation of an Editorial Advisory Board comprising of eminent professionals from the industry. With their guidance, we hope to be able to deliver more value to our readers over the coming months. Please refer to Page 3 for details on the board.

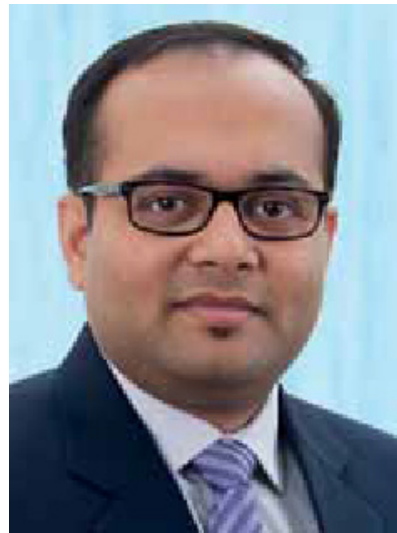

autotechreview.com

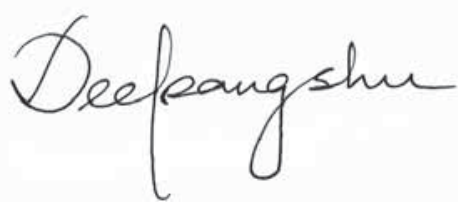

DEEPANGSHU DEV SARMAH

Editor-in-Chief

New Delhi, October 2016 